\title{
Postoperative renal function in patients is unaltered after robotic-assisted radical prostatectomy
}

\author{
Jae Hyun Ahn, Choon Hak Lim, Hye In Chung, Seong Uk Choi, Seung Zoo Youn, and Hae Ja Lim \\ Department of Anesthesiology and Pain Medicine, Korea University College of Medicine, Seoul, Korea
}

Background: Pneumoperitoneum with an intra-abdominal pressure (IAP) of $14 \mathrm{mmHg}$ is known to decrease renal function. Robotic-assisted radical prostatectomy (RARP) requires an IAP of more than $15 \mathrm{mmHg}$ for operation. Therefore, we retrospectively investigated whether patients who underwent RARP experienced renal insufficiency during the postoperative period (at postoperative days 7 and 30).

Methods: One hundred patients who underwent RARP were enrolled in this study. Preoperative serum blood urea nitrogen $(\mathrm{BUN})$ and serum creatinine $(\mathrm{Cr})$ levels were measured. Creatinine clearance $(\mathrm{CrCl})$ was calculated using the Cockcroft and Gault formula. $\mathrm{CrCl}$ was calculated at 1 day before surgery (baseline), $2 \mathrm{hr}$ postoperatively, and at 1 , 3,7 , and 30 days postoperatively ( $\mathrm{POD} 1, \mathrm{POD} 3, \mathrm{POP} 7$, and POD 30). Patients were assigned to abnormal $\mathrm{CrCl}(\mathrm{n}=$ $52)$ or normal $\mathrm{CrCl}$ groups $(\mathrm{n}=48)$ on the basis of these measurements.

Results: Significant inter-group differences in $\mathrm{BUN}, \mathrm{Cr}$, and $\mathrm{CrCl}$ were observed at all postoperative time points. BUN and $\mathrm{Cr}$ decreased significantly at postoperative $2 \mathrm{hr}$ and POD 1, 3, and 7 versus baseline in both groups, whereas $\mathrm{CrCl}$ increased significantly at postoperative $2 \mathrm{hr}$ and POD 1, 3, and 7 versus baseline in both groups. However, BUN, Cr, and $\mathrm{CrCl}$ were similar at POD 30 and preoperatively in the two groups.

Conclusions: RAPR, which requires an IAP of 15-20 $\mathrm{mmHg}$ for more than $4 \mathrm{hr}$, does not induce renal dysfunction during the postoperative period, and even in those patients with an abnormal CrCl. (Korean J Anesthesiol 2011; 60: 192-197)

Key Words: Pneumoperitoneum, Renal function.

Received: July 15, 2010. Revised: October 8, 2010. Accepted: October 12, 2010.

Corresponding author: Choon Hak Lim, M.D., Ph.D., Depatment of Anesthesiology and Pain Medicine, Korea University Medical Center, Anam-5 ga, Seongbuk-gu, Seoul 136-705, Korea. Tel: 82-2-920-5632, Fax: 82-2-928-2275, E-mail: yourejoice@korea.ac.kr

This study was supported by grants from the Institute of Medical System Engineering (iMSE) in the Gwangju Institute of Science and Technology (GIST), Republic of Korea.

(c) This is an open-access article distributed under the terms of the Creative Commons Attribution Non-Commercial License (http:// creativecommons.org/licenses/by-nc/3.0/), which permits unrestricted non-commercial use, distribution, and reproduction in any medium, provided the original work is properly cited. 


\section{Introduction}

Increased intra-abdominal pressure (IAP) has long been associated with oliguria. A pneumoperitoneum at $7 \mathrm{mmHg}$ is known to have no adverse effects on renal hemodynamics or excretory functions, but an IAP of $14 \mathrm{mmHg}$ is known to decrease the glomerular filtration rate (GFR) by $53 \%$ and the renal blood flow (RBF) by $46 \%$, and to impair urine output markedly by $10 \%$ and sodium excretion by $20 \%$ [1]. Nonetheless, many authors have insisted that laparoscopic surgery with intraperitoneal insufflation is associated with transient oliguria, but without any apparent sequelae [2-4].

A recent report demonstrated that erythrocyte velocities in cortical peritubular capillaries were significantly reduced when IAP was increased from 8 to $12 \mathrm{mmHg}$ after 5 minutes of pneumoperitoneum, and that tubular damage of the subcapsular renal cortex, including tubular vacuolation, cell detachment, and tubular damage, developed 2 hours after starting laparoscopic surgery using a sustained pneumoperitoneal pressure of $20 \mathrm{mmHg}$. Accordingly, it was recommended that the duration of surgery should be considered in addition to IAP [5].

Robotic-assisted radical prostatectomy (RARP) requires long operation times (often longer than 4 hours) and an IAP of more than $15 \mathrm{mmHg}$ with the patient in the deep Trendelenburg position. In patients that undergo RARP, urine output cannot be monitored due to urine spillover into the peritoneal space because of bladder neck dissection [6]. Therefore, in this retrospective study, we investigated whether patients that underwent RARP experienced renal insufficiency during the postoperative period (postoperative day 7 and 30: POD 7 and 30).

\section{Materials and Methods}

After obtaining Institutional Review Board approval, we enrolled patients that had undergone RARP from July 2007 to July 2009. Patients who had an ASA physical status higher than III were excluded. Patients with massive bleeding during the operation were also excluded. Remifentanil, propofol, and rocuronium were used as induction agents. Anesthesia was maintained with remifentanil $(0.25-0.40 \mu \mathrm{g} / \mathrm{kg} / \mathrm{min})$ and desflurane (5-8 vol\%). Intraoperative MAP and HR were within $\pm 20 \%$ of preoperative values. The bispectral index (BIS) was maintained at 50-60 during the operation. A robot system (Da Vinci robot system; Intuitive Surgical, Mountain View, CA) was used. A pneumoperitoneum was created by $\mathrm{CO}_{2}$ insufflation ( $15 \mathrm{mmHg}$ ) and patients were positioned in a $30^{\circ}$ head-down position. The pneumoperitoneum was released after prostate removal.

Creatinine clearance $(\mathrm{CrCl})$ was calculated using Cockcroft and Gault's formula at 1 day before surgery (baseline), postoperative $2 \mathrm{hr}$, and POD 1, POD 3, POD 7, and POD 30 [7]: $\mathrm{CrCl}$ $=(140-$ age $) \times$ ideal body weight $/$ (serum creatinine $\times 72)$.

The normal $\mathrm{CrCl}$ range for men younger than $40 \mathrm{yr}$ is $90-139$ $\mathrm{ml} / \mathrm{min}$, and for men over $40 \mathrm{yr}$, normal values decrease by 6.5 $\mathrm{ml} / \mathrm{min}$ for each decade of life. The normal $\mathrm{CrCl}$ ranges for men $40-49 \mathrm{yr}$ is $83.5-132.5 \mathrm{ml} / \mathrm{min}$; for men $50-59 \mathrm{yr}$ is $77-126$ $\mathrm{ml} / \mathrm{min}$; for men $60-69 \mathrm{yr}$ is $70.5-119.5 \mathrm{ml} / \mathrm{min}$; and for men

Table 1. Patients' Characteristics and Data from the Perioperative Period

\begin{tabular}{|c|c|c|c|}
\hline & Normal CrCl group $(\mathrm{n}=48)$ & Abnormal $\mathrm{CrCl}(\mathrm{n}=52)$ & $P$ value \\
\hline $\operatorname{Age}(y r)$ & $61.50 \pm 5.19$ & $64.60 \pm 6.75$ & 0.01 \\
\hline $40-49 / 50-59 / 60-69 / 70-79 \mathrm{yr}$ & $0 / 16 / 29 / 3$ & $2 / 10 / 27 / 13$ & NS \\
\hline Weight (kg) & $65.78 \pm 8.59$ & $68.31 \pm 9.22$ & NS \\
\hline Height $(\mathrm{cm})$ & $167.83 \pm 5.11$ & $166.83 \pm 5.06$ & NS \\
\hline \multicolumn{4}{|l|}{ Underlying disease } \\
\hline DM & 2 & 9 & 0.03 \\
\hline Hypertension & 19 & 24 & NS \\
\hline Ischemic heart disease & 0 & 1 & NS \\
\hline \multicolumn{4}{|l|}{ Preoperative medication } \\
\hline Nifedipine & 6 & 14 & NS \\
\hline \multicolumn{4}{|l|}{ Preoperative values } \\
\hline $\mathrm{Hb}(\mathrm{g} / \mathrm{dl})$ & $14.36 \pm 0.95$ & $14.35 \pm 1.35$ & NS \\
\hline BUN (mg/dl) & $15.83 \pm 3.53$ & $17.61 \pm 3.56$ & 0.01 \\
\hline $\mathrm{Cr}(\mathrm{mg} / \mathrm{dl})$ & $0.88 \pm 0.08$ & $1.08 \pm 0.11$ & $<0.001$ \\
\hline $\mathrm{CrCl}(\mathrm{ml} / \mathrm{min})$ & $79.35 \pm 7.79$ & $61.33 \pm 7.55$ & $<0.001$ \\
\hline Corrective $\mathrm{CrCl}\left(\mathrm{ml} / \mathrm{min} / 1.73 \mathrm{~m}^{2}\right)$ & $78.81 \pm 8.27$ & $59.90 \pm 7.23$ & $<0.001$ \\
\hline Operation time (min) & $290.81 \pm 43.35$ & $298.88 \pm 84.44$ & NS \\
\hline Pneumoperitoneum time (min) & $256.06 \pm 43.03$ & $260.17 \pm 83.91$ & NS \\
\hline \multicolumn{4}{|l|}{ Fluid balance } \\
\hline Crystalloid (ml) & $2,143.75 \pm 790.21$ & $2,379.81 \pm 916.15$ & NS \\
\hline Colloid (ml) & $954.17 \pm 164.97$ & $939.42 \pm 155.40$ & NS \\
\hline
\end{tabular}

Values are mean \pm SD or number of patients. CrCl: creatinine clearance. 
$70-79 \mathrm{yr}$ is $64-113 \mathrm{ml} / \mathrm{min}$.

The $\mathrm{CrCl}$ value less than the minimum value was considered to be abnormal (e.g. $\mathrm{CrCl}<83.5 \mathrm{ml} / \mathrm{min}$ in patients aged $40-49$ yr). Patients were allocated either to the abnormal $(n=52) \mathrm{CrCl}$ group or normal $\mathrm{CrCl}$ group $(\mathrm{n}=48)$ using these ranges.

Serum BUN and Cr levels were checked on POD 1, 3, and 7. $\mathrm{CrCl}$ values were calculated. $\mathrm{CrCl}$ values were corrected for body surface area (BSA) using the following equation: for men, corrected $\mathrm{CrCl}=\mathrm{CrCl}$ (as determined using the Cockcroft and Gault formula) $\times 1.73 \mathrm{~m}^{2} /$ the patient's body surface area (BSA) [8]

Statistical analyses were performed using SAS v 8.1 (SAS Institute Inc., Cary, NC, USA) for Windows ${ }^{\circledR}$. All results are expressed as mean \pm SD or as numbers of patients. Student's t test, the Chi-square test, or the Mantel-Haenszel Chi-square test were used to determine significant inter-group differences. Results were analyzed using repeated-measures analysis of

A

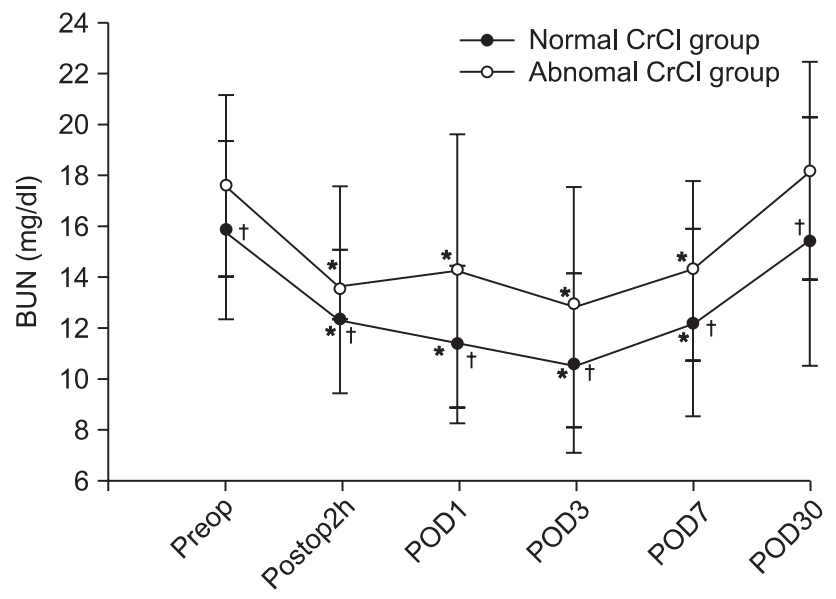

C

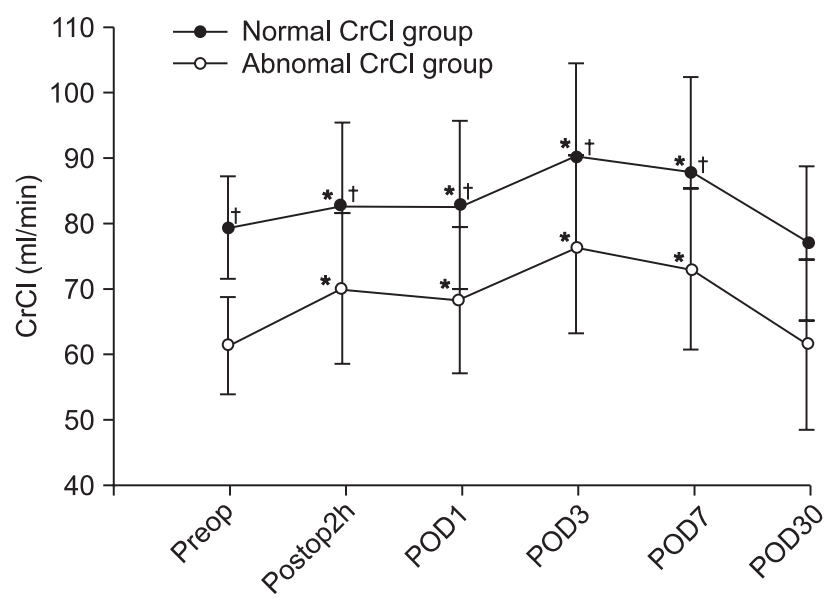

variance within each group. When a significant main effect was detected, contrast was used for post hoc testing. $\mathrm{P}$ value of $<0.05$ were considered significant. A minimum sample size calculation was performed with the assumption that a $10 \%$ change in $\mathrm{CrCl}$ on postoperative 7 day in the abnormal $\mathrm{CrCl}$ group was clinically significant based on data from normal $\mathrm{CrCl}$ patients. A minimum of 45 patients in each group was necessary to detect a difference in postoperative renal function change using a two-tailed test with a probability of a type I error $(\alpha)$ of 0.05 and a probability of a type II error ( $\beta$ ) of 0.1 (power 90\%).

\section{Results}

Patient characteristics and data from the perioperative period are summarized in Table 1. No significant differences were observed between the normal and abnormal $\mathrm{CrCl}$ groups

B

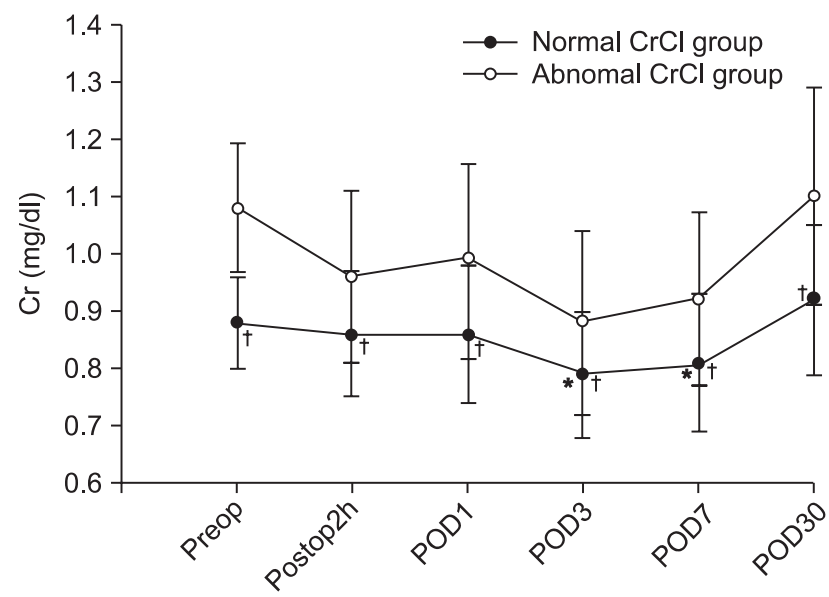

D

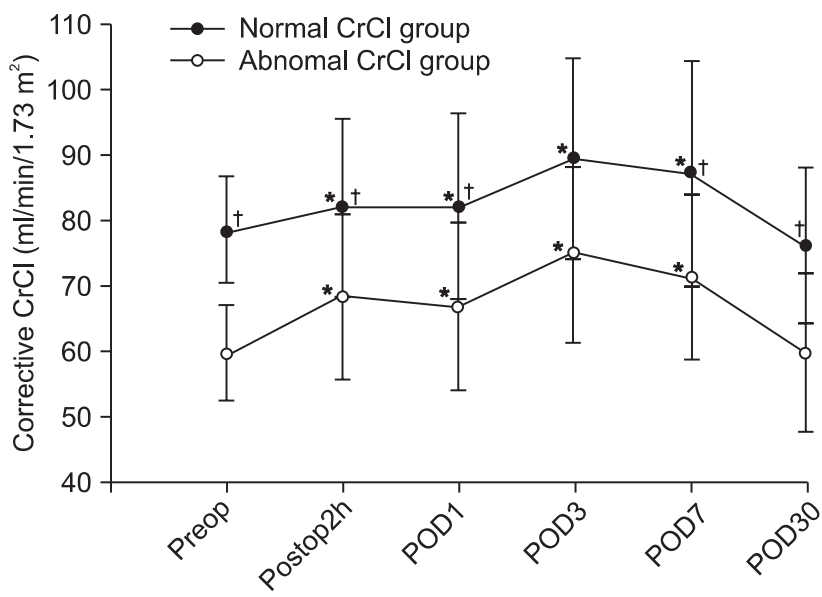

Fig. 1. Changes in $\mathrm{BUN}, \mathrm{Cr}, \mathrm{CrCl}$, and corrected $\mathrm{CrCl}$ in the normal $\mathrm{CrCl}$ group and abnormal $\mathrm{CrCl}$ group. Normal CrCl group: patients with a normal $\mathrm{CrCl}$ preoperatively; abnormal $\mathrm{CrCl}$ group: patients with an abnormal $\mathrm{CrCl}$ preoperatively. $* \mathrm{P}<0.05$ compared with the preoperative value within each group, ${ }^{\dagger} \mathrm{P}<0.05$ between groups. 
except for age, a preoperative history of diabetes mellitus, and preoperative renal function. Patient age was significantly higher in the abnormal $\mathrm{CrCl}$ group than the normal $\mathrm{CrCl}$ group, but the age distribution was not significantly different between the two groups.

Significant inter-group differences in $\mathrm{BUN}, \mathrm{Cr}, \mathrm{CrCl}$, and corrected $\mathrm{CrCl}$ were observed at all postoperative time points (Fig. 1). BUN and Cr decreased significantly at postoperative 2 hr and at POD 1, 3, and 7 versus baseline in both groups. $\mathrm{CrCl}$ and corrected $\mathrm{CrCl}$ were significantly higher at postoperative $2 \mathrm{hr}$ and at POD 1, 3, and 7 compared with baseline in both groups. However, BUN, $\mathrm{Cr}, \mathrm{CrCl}$ and corrected $\mathrm{CrCl}$ were similar to baseline at POD 30 in both groups.

The same pattern was seen for the patients in their $60 \mathrm{~s}(60-69$ $\mathrm{yr}$ ) of the abnormal and normal $\mathrm{CrCl}$ group (Fig. 2).

No major postoperative complication that required reoperation or postoperative intensive care occurred in both groups.

\section{Discussion}

The results of this retrospective study show that RAPR, which requires the patient to be in the deep Trendelenburg position with an IAP of 15-20 $\mathrm{mmHg}$ for more than $4 \mathrm{hr}$, does not induce renal dysfunction during the postoperative period.

Pneumoperitoneum has been previously shown to reduce GFR and RBF and to cause oliguria [1,9]. Although the mechanism underlying this phenomenon is largely unknown, direct compression of the renal parenchyma and renal vein, and the release of vasoconstrictors, such as vasopressin, angiotensin II, and catecholamines, have been well documented to reduce intraoperative urine output $[10,11]$. Even though oliguria
A

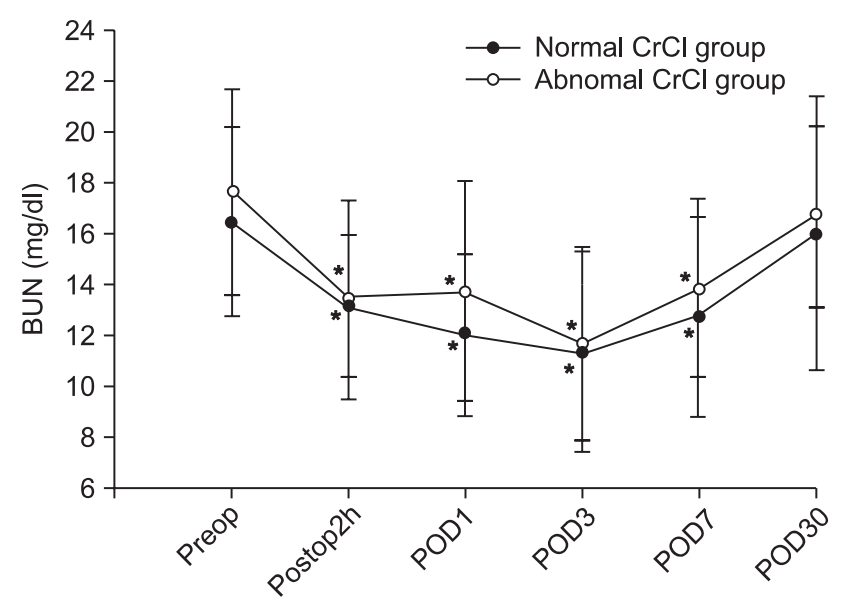

C

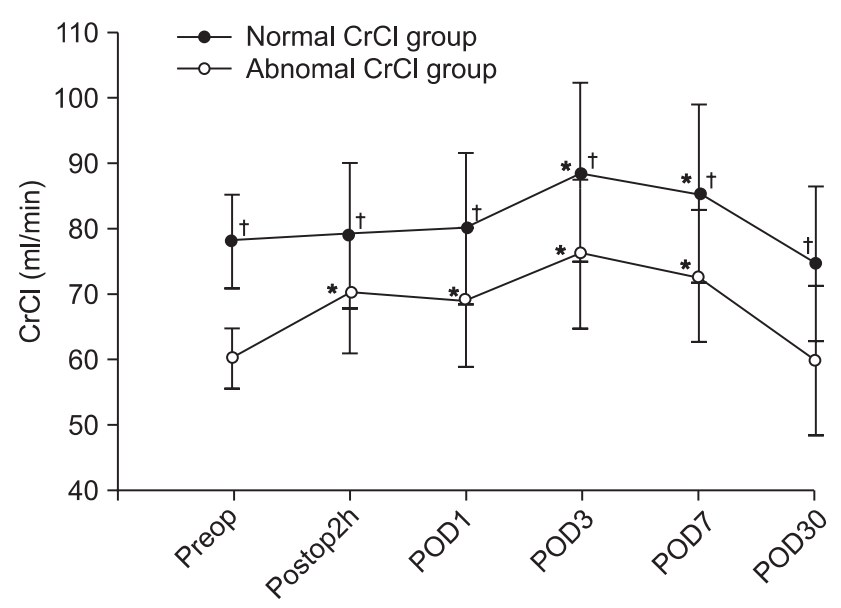

B

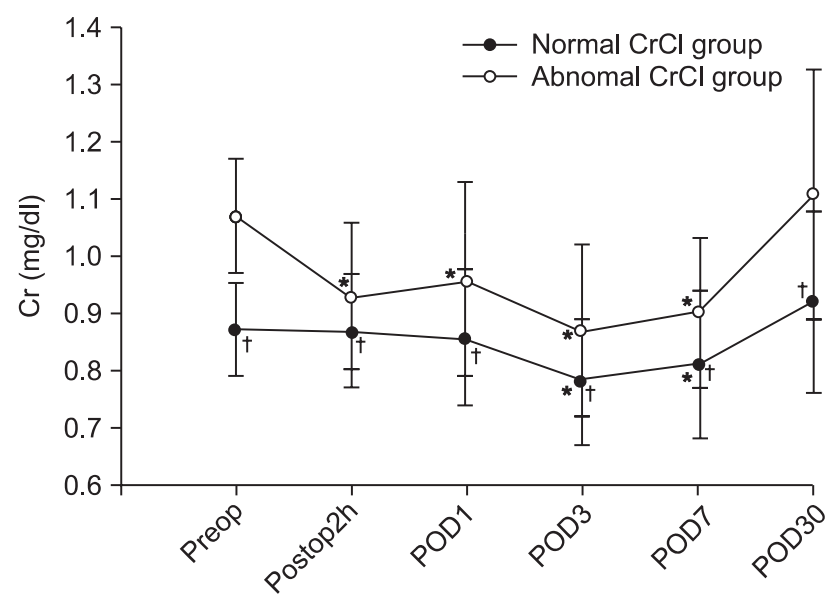

D

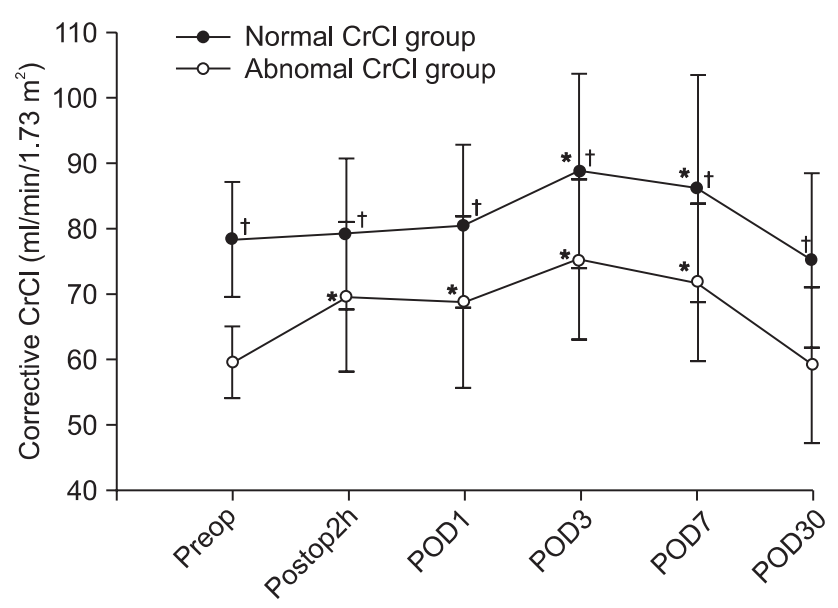

Fig. 2. Changes in $\mathrm{BUN}, \mathrm{Cr}, \mathrm{CrCl}$ and corrected $\mathrm{CrCl}$ in the normal $\mathrm{CrCl}$ group and abnormal $\mathrm{CrCl}$ group aged $60-69$ yr. Normal $\mathrm{CrCl}$ group: patients with a normal $\mathrm{CrCl}$ preoperatively; abnormal $\mathrm{CrCl}$ group: patients with an abnormal $\mathrm{CrCl}$ preoperatively. $* \mathrm{P}<0.05$ compared with the preoperative value within each group, ${ }^{\dagger} \mathrm{P}<0.05$ between groups. 
is known to be transient and to resolve after desufflation in men [2-4], the use of vasodilators such as nitroglycerine [1], diltiazem [12], and nicardipine [6], and low doses of dopamine [13] has been suggested to prevent renal dysfunction during pneumoperitoneum without causing any hemodynamic derangement.

In a recent study, it was found that histologic changes such as tubular vaculoation, cell detachment, and tubular damage of the subcapsular renal cortex occurred after 2 hours of laparoscopic surgery in a porcine model (pneumoperitoneal pressure maintained at $20 \mathrm{mmHg}$ ) [5]. In this study, erythrocyte velocity in the cortical peritubular capillaries was found to decrease when the carbon dioxide pneumoperitoneum pressure was $12 \mathrm{mmHg}$; erythrocyte velocity improved rapidly when the pressure was reduced to $8 \mathrm{mmHg}$. Thus, those authors recommended that a pneumoperitoneal pressure of less than $8 \mathrm{mmHg}$ be used for laparoscopic surgery to protect the renal microcirculation [5].

However, RARP is becoming a routine procedure for the treatment of prostate cancer, and requires marked headdown tilting and an IAP of more than $15 \mathrm{mmHg}$ for more than 4 hours. An extreme head-down tilt markedly increases the central venous pressure and it may further compromise renal perfusion, and it is also associated with a $40-50 \%$ decrease in cardiac output during laparoscopic procedures, and even at an IAP of 10-12 mmHg [14,15]. Furthermore, almost all patients that undergo prostate resection are over 40 years old and nephrosclerosis and glomerulosclerosis occur to some extent in most people after the fourth decade of life, which reduces the number of functional nephrons by $\sim 10 \%$ for each 10 years of age after 40 [16]. Thus, the effect of pneumoperitoneum during RAPR on renal function might be different from other forms of laparoscopic surgery. Postoperative renal function should be evaluated in patients undergoing RAPR and the need for active treatment to prevent renal dysfunction should be reexamined.

In the present study, renal function profiles were evaluated as $\mathrm{CrCl}$. Calculated and corrected $\mathrm{CrCl}$ levels were used rather than measured $\mathrm{CrCl}$ levels to estimate GFR, because measured $\mathrm{CrCl}$ levels are inaccurate and imprecise due to the inaccurate collection of urine samples. Calculated $\mathrm{CrCl}$ has been reported to provide a better estimate of GFR and a corrected $\mathrm{CrCl}$, which corrects for BSA levels, has been reported to provide more accurate estimations of GFR than measured $\mathrm{CrCl}$ when compared with inulin clearance [17-19].

Immediate postoperative renal dysfunction was expected in patients undergoing RAPR. Interestingly, however, BUN and $\mathrm{Cr}$ decreased while $\mathrm{CrCl}$ and corrected $\mathrm{CrCl}$ increased significantly versus baseline at postoperative $2 \mathrm{hr}$ and also at POD 1, 3, and 7 in both normal and abnormal $\mathrm{CrCl}$ groups. This finding is consistent with previous laparoscopic studies. Nishio and colleagues [20] demonstrated that urinary output decreased significantly during insufflation and increased significantly after desufflation during laparoscopic adrenalectomy. Other clinical and animal studies have shown that renal function profiles using $\mathrm{CrCl}$ or estimated GFR levels were significantly or substantially elevated after laparoscopic surgery (an IAP of 15 mmHg for more than $3 \mathrm{hr}$ ) on POD 1 and $3[1,2,6]$.

These renal function profiles returned to the preoperative values on POD 30 in all the patients. Even patients with abnormal preoperative $\mathrm{CrCl}$ levels were found to have a similar renal function on POD 30 compared with their preoperative values. In our study, no patient showed postoperative renal insufficiency or renal failure. In an animal study, it was found that pigs exposed to a $\mathrm{CO}_{2}$ pneumoperitoneum at $20 \mathrm{mmHg}$ for $6 \mathrm{hr}$ to mimic a complex laparoscopy had elevated levels of $\mathrm{N}$-methyl- $\beta$-D-glucosaminidase in their urine. However, GFRs were found to have returned to the preexposure levels when reassessed 1 week after pneumoperitoneum, even in swine with chronic renal failure [21].

Our findings suggest that postoperative renal function in patients who underwent RARP is unaltered and the administration of intraoperative vasodilators is not required to prevent renal dysfunction for laparoscopic procedures lasting more than $2 \mathrm{hr}$ (up to $4 \mathrm{hr}$ ) at an IAP of $15 \mathrm{mmHg}$. However, in this retrospective study, we excluded the patients with an ASA physical status class III or more, and the severity of the patients' renal insufficiency was not evaluated. Therefore, it is unclear if our findings can be extrapolated to patients with severe renal insufficiency and hemodynamic derangement.

In summary, renal function was not reduced on POD 7 and 30 in patients who underwent RARP, and even in patients with an abnormal preoperative $\mathrm{CrCl}$ level.

\section{References}

1. Bishara B, Karram T, Khatib S, Ramadan R, Schwartz H, Hoffman A, et al. Impact of pneumoperitoneum on renal perfusion and excretory function: beneficial effects of nitroglycerine. Surg Endosc 2009; 23: 568-76.

2. Nguyen NT, Perez RV, Fleming N, Rivers R, Wolfe BM. Effect of prolonged pneumoperitoneum on intraoperative urine output during laparoscopic gastric bypass. J Am Coll Surg 2002; 195: 47683.

3. McDougall EM, Monk TG, Wolf JS Jr, Hicks M, Clayman RV, Gardner S, et al. The effect of prolonged pneumoperitoneum on renal function in an animal model. J Am Coll Surg 1996; 182: 317-28.

4. Koivusalo AM, Kellokumpu I, Scheinin M, Tikkanen I, Halme L, Lindgren L. Randomized comparison of the neuroendocrine response to laparoscopic cholecystectomy using either conventional or abdominal wall lift techniques. Br J Surg 1996; 83: 1532-6.

5. Sassa N, Hattori R, Yamamoto T, Kato M, Komatsu T, Matsukawa $\mathrm{Y}$, et al. Direct visualization of renal hemodynamics affected by 
carbon dioxide-induced pneumoperitoneum. Urology 2009; 73: 311-5.

6. Cho JE, Shim JK, Chang JH, Oh YJ, Kil HK, Rha KH, et al. Effect of nicardipine on renal function after robot-assisted laparoscopic radical prostatectomy. Urology 2009; 73: 1056-60.

7. Zhao WY, Zeng L, Zhu YH, Wang LM, Zhou MS, Han S, et al. A comparison of prediction equations for estimating glomerular filtration rate in Chinese potential living kidney donors. Clin Transplant 2009; 23: 469-75.

8. Robertshaw M, Lai KN, Swaminathan R. Prediction of creatinine clearance from plasma creatinine: comparison of five formulae. Br J Clin Pharmacol 1989; 28: 275-80.

9. Miki Y, Iwase K, Kamiike W, Taniguchi E, Sakaguchi K, Sumimura J, et al. Laparoscopic cholecystectomy and time-course changes in renal function. The effect of the retraction method on renal function. Surg Endosc 1997; 11: 838-41.

10. Myre K, Rostrup M, Eriksen M, Buanes T, Raeder J, Stokland O. Increased spillover of norepinephrine to the portal vein during COpneumoperitoneum in pigs. Acta Anaesthesiol Scand 2004; 48: 44350 .

11. Youssef MA, saleh Al-Mulhim A. Effects of different anesthetic techniques on antidiuretic hormone secretion during laparoscopic cholecystectomy. Surg Endosc 2007; 21: 1543-8.

12. Kim JY, Lee KC, Kim HS, Jo YY, Kwak HJ. Effect of diltiazem on kidney function during laparoscopic surgery. Surg Endosc 2009; 23: 1785-90.

13. Pérez J, Taurá P, Rueda J, Balust J, Anglada T, Beltran J, et al. Role of dopamine in renal dysfunction during laparoscopic surgery. Surg Endosc 2002; 16: 1297-301.

14. Hirvonen EA, Nuutinen LS, Kauko M. Hemodynamic changes due to Trendelenburg positioning and pneumoperitoneum during laparoscopic hysterectomy. Acta Anaesthesiol Scand 1995; 39: 94955.

15. Koivusalo AM, Pere P, Valjus M, Scheinin T. Laparoscopic cholecystectomy with carbon dioxide pneumoperitoneum is safe even for high-risk patients. Surg Endosc 2008; 22: 61-7.

16. Guyton AC, Hall JE. Textbook of Medical Physiology. 11th ed. Philadelphia, Elsevier. 2006, pp 402-15.

17. Robert S, Zarowitz BJ, Peterson EL, Dumler F. Predictability of creatinine clearance estimates in critically ill patients. Crit Care Med 1993; 21: 1487-95.

18. Spinler SA, Nawarskas JJ, Boyce EG, Connors JE, Charland SL, Goldfarb S. Predictive performance of ten equations for estimating creatinine clearance in cardiac patients. Iohexol Cooperative Study Group. Ann Pharmacother 1998; 32: 1275-83.

19. Rostoker G, Andrivet P, Pham I, Griuncelli M, Adnot S. A modified Cockcroft-Gault formula taking into account the body surface area gives a more accurate estimation of the glomerular filtration rate. J Nephrol 2007; 20: 576-85.

20. Nishio S, Takeda H, Yokoyama M. Changes in urinary output during laparoscopic adrenalectomy. BJU Int 1999; 83: 944-7.

21. Cisek LJ, Gobet RM, Peters CA. Pneumoperitoneum produces reversible renal dysfunction in animals with normal and chronically reduced renal function. J Endourol 1998; 12: 95-100. 